\title{
ПРЕДСТАВЛЕНИЯ О МЕГАПОЛИСЕ И СОЦИАЛЬНО- ПСИХОЛОГИЧЕСКАЯ ПРЕСЫЩЕННОСТЬ МОЛОДЕЖИ УСЛОВИЯМИ ПРОЖИВАНИЯ В ГОРОДЕ
}

Исследование выполнено при финансовой поддержке РФФИ. Проект № 20-013-00461 Дробышева Т.В., Ларионов И.В. («ИП РАН», Москва, Россия) tdrobysheva@mail.ru, ivlar16@gmail.com

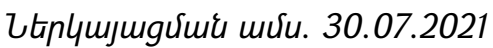

9pmpunuर्जuध uर्रu. 09.08.2021

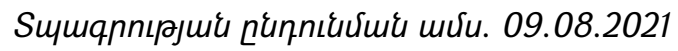

В статье рассматривается проблема связи социально-психологической пресыщенности и социальных представлений о мегаполисе. Противоречивость восприятия молодежью условий проживания в мегаполисе объясняется тем, что ядро и периферия социального представления включают суждения разной модальности. Обнаружена связь между элементами периферии представления и показателями социально-психологической пресыщенности. Показано, пресыщенность молодежи условиями жизни в городе связана с восприятием ими проблемных сторон жизни в мегаполисе. Выбор стратегий совладания с состоянием пресыщенности определяется переживанием респондентами спектра негативных эмоций и чувств.

Ключевые слова: социально-психологическая пресыщенность, социальные представления, социальная психология города.

DOI: https://doi.org/10.46991/SBMP/2021.4.2.133

Результаты психологических исследований репрезентаций города свидетельствуют о том, что городская среда воспринимается ее жителями как сложноорганизованное жизненное пространство, отношение к которому субъективно обусловлено [1; 3; 6 и мн.др.]. В рамках социально-психологического подхода к изучению города специалисты подчеркивают коллективную природу репрезентации городской среды - представления о городе, формируясь индивидуально, приобретают коллективный характер, т.е. отражают взгляды конкретной социальной группы [4; 9].

Восприятие городской среды ее жителями амбивалентно. С одной стороны, она предоставляет множество возможностей для самореализации и проведения досуга, с другой стороны, является источником постоянных стрессов и переживаний [3]. Эта проблема особенно актуальна для молодых жителей мегаполиса - их представления о городе свидетельствуют как о 
субъективной значимости, ценности города, так и неудовлетворенности условиями проживания в нем. Последнее отражается в сниженных показателях психологического и социального благополучия молодежи [6, 7, и др.], их готовности к миграции [8]. С позиций развиваемого нами подхода это противоречие может быть объяснено, в том числе социально-психологической пресыщенностью (СПП) молодежи условиями проживания в мегаполисе [2]. Данное состояние характерно для жителей современных мегаполисов. Оно проявляется в виде эмоциональных переживаний широкого спектра, вызванных чрезмерной информатизацией городской среды, монотонным ритмом жизни, перенаселенностью, навязанными тесными контактами с чужими людьми, рекламой и другими явлениями городской жизни, которые воспринимаются горожанами как источники социальной и фризической угрозы. В зависимости от интенсивности и модальности переживаний, преодолевая это состояние, жители мегаполиса выбирают стратегии совладания или избегания, тем самым актуализируя функцию «защиты» психики от воздействий городской среды. К примеру, в наших ранних работах было обнаружено, что выраженное состояние социально-психологической пресыщенности условиями жизни в мегаполисе в группе молодых горожан характеризовалось переживанием тревоги, раздражения, отвращения, а совладание с ним проявилось в ограничении контактов с навязанной рекламой (отключить рекламные сообщения на гаджете, надеть наушники в метро, не читать наружную рекламу, и т.п.), в готовности резко прерывать надоевшую беседу с другими (особенно, если информации много и она не столь значима), общаться только с самыми близкими и по необходимости, и т.п..

Выраженность СПП связана с представлениями горожан об условиях жизни в городе. Опираясь на структурный подход Ж.-К. Абрика [9], разработанный в рамках концепции социальных представлений С. Московиси, сфрормулировали цель исследования - изучить связь эмоциональных и поведенческих проявлений социально-психологической пресыщенности и элементов социального представления о мегаполисе. Цель была конкретизирована в следующих задачах: 1) проанализировать структуру социального представления о мегаполисе; 2) выполнить анализ связи между элементами социального представления о неудовлетворенности проживанием в городе и показателями социально-психологической пресыщенности. В исследовании Т.П. Емельяновой [3] было обнаружено, что ядро СП молодежи о мегаполисе включает элементы (суждения), свидетельствующие в целом о позитивном восприятии качества жизни в городе. Негативный аспект восприятия мегаполиса в ядерном компоненте был представлен одним суждением о плохой экологической обстановке в городе. Остальные суждения были вытеснены на периферию СП. Опираясь на данные коллег, сформулировали предположение. 
Основная гипотеза исследования - выраженные показатели социальнопсихологической пресыщенности будут связаны с суждениями о неудовлетворенности проживанием в городе, вошедшими в периферийную часть СП.

Описание выборки. В исследовании приняли участие 159 человек в возрасте от 19 до 30 лет, из них: 40\% юношей и 60\% девушек.

Методы и методики. Для измерения социально-психологической пресыщенности применяли авторские опросники, включающие разные суждения, выделенные на пилотажном этапе работы в процессе фрокусгрупповых исследований. Конативные показатели СП пресыщенности (стратегии поведения) выявляли с помощью опросника, построенного по типу биполярных шкал. Он включал 10 наиболее часто упоминаемых высказываний («активно ищу иные источники удовольствия в мегаполисе», «резко прерываю надоевшую беседу», «стремлюсь оградить себя от назойливой рекламы любыми способами», и т.п.). Психометрическая проверка согласованности пунктов опросника показала его достаточный уровень надежности ( $\alpha=0,720$; mean=3,65; St.Dev.=0,21).

Опросник, ориентированный на выявление эмоциональных переживаний респондентов, вызванных различными явлениями городской жизни, был построен по типу методики репертуарной решетки Келли. Данные явления определялись участниками исследования как источники их пресыщенности условиями проживания в мегаполисе. После подсчета наиболее часто повторяющихся высказываний в матрицу внесли 11 явлений (реклама в городе; много альтернатив выбора товаров, проведения досуга; вынужденное общение; много контактов в течение дня, и т.п.). Список переживаемых эмоциональных переживаний включал: беспокойство, тревогу; разочарование; апатию, скуку; раздражение; радость, воодушевление; отвращение; веру, надежду; удивление, интерес. Респондентам было предложено оценить по 5балльной шкале Лайкерта выраженность восьми эмоций, вызванных одиннадцатью явлениями городской жизни. Проверка согласованности пунктов второго опросника показала: $\alpha=0,89$; mean=2.1; St.Dev.=0,78.

Для выявления структуры социального представления применяли опросник Т.П. Емельяновой “Социальные представления о мегаполисе» [3] содержащий 26 утверждений, направленных на выявление представлений горожан о жизни в мегаполисе. Респондентам также предлагалось оценить свое согласие с суждениями по 5-балльной шкале. Для выявления социодемографических характеристик респондентов применяли анкетирование.

Методы статистического анализа: частотный анализ, корреляционный анализ (r-Spearman), описательные статистики.

Основные результаты. Структуру СП о мегаполисе рассчитывали по фрормуле подсчета коэфффициента позитивных ответов Ж.К. Абрика (ТСР), 
опубликованной в работе Т.П. Емельяновой [4, с. 243-244]. Были выделены ядро и периферия СП. К ядру были отнесены суждения, значения коэффрициентов которых были выше среднего плюс среднеквадратичное отклонение. Суждения, отнесенные к ядру СП, свидетельствовали о субъективной значимости для респондентов фракторов комфортной жизни в мегаполисе: «В мегаполисе большой выбор товаров и услуг» (значение ТСР=88); «Культурная жизнь мегаполиса разнообразна» (84); «В мегаполисе хорошо организованная инфраструктура» (79); «Медицина в мегаполисе на более высоком уровне, чем в маленьких городах» (76); «Жить в наше время в мегаполисе гораздо комфортнее, чем раньше» (72); “Образование в мегаполисе на высоком уровне» (69). Суждения, свидетельствующие о неудовлетворенности условиями жизни в мегаполисе, были отнесены к зоне периферии, близкой я ядру «Экология мегаполиса подрывает здоровье» (56); Жизнь в мегаполисе сопровождается большим количеством стрессов (52) - а также собственно периферии СП: Большое количество межличностных контактов в мегаполисе является стрессом (39); Безопасность в мегаполисе оставляет желать лучшего (35); Безличный характер общения в мегаполисе обесценивает отношения (33); Экономика мегаполиса оставляет желать лучшего (25); Информатизация является скорее минусом, чем плюсом жизни в большом городе (19). Концептуально ядерный компонент СП обладает устойчивостью по отношению к внешним воздействиям, он связан с коллективными ценностями и нормами. Периферия в структуре СП, наоборот, характеризуется динамичностью, отвечает на адаптацию к быстро изменяющимся внешним условиям жизни и связана с индивидуальной памятью [9]. В связи с этим пограничное положение суждений о проблеме экологии и наличии стрессов в мегаполисе косвенно свидетельствует об их относительной устойчивости.

Итак, содержание ядра СП о мегаполисе свидетельствует о позитивном восприятии условий жизни в городе. Однако включение двух суждений в околоядерную зону СП указывает на их потенциальную возможность перехода в ядро СП в разных ситуациях ухудшения экологической обстановки в городе. Расположение большинства негативных суждений на периферии СП показывает, что они имеют индивидуальную значимость - отражают обеспокоенность индивида, а не социальной группы, в которую он включен. Общая направленность этих суждений свидетельствует о неудовлетворенности условиями проживания в городе. Последующий корреляционный анализ показателей СПП и периферийных элементов СП о мегаполисе показал следующее. 
Таблица 1.

Связь между негативными суждениями о мегаполисе и эмоциональными показателями социально-психологической пресыщенности.

\begin{tabular}{|c|c|c|c|c|c|}
\hline $\begin{array}{l}\text { Суждения о мегаполисе / эмоциональные } \\
\text { переживания }\end{array}$ & 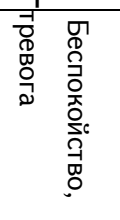 & 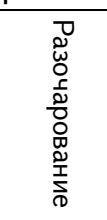 & 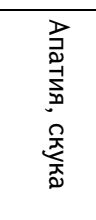 & 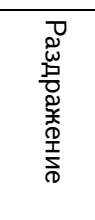 & 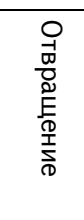 \\
\hline $\begin{array}{l}\text { Жизнь в мегаполисе сопровождается большим } \\
\text { количеством стрессов }\end{array}$ & $0,18^{*}$ & & & $0,2^{*}$ & \\
\hline $\begin{array}{l}\text { Информатизация является скорее минусом, чем } \\
\text { плюсом жизни в большом городе }\end{array}$ & $0,26^{* *}$ & $0,16^{*}$ & & & \\
\hline $\begin{array}{l}\text { Большое количество межличностных контактов } \\
\text { в мегаполисе является стрессом }\end{array}$ & $0,22^{* *}$ & $0,21^{* *}$ & $0,21^{* *}$ & $0,31^{* *}$ & $0,21^{* *}$ \\
\hline $\begin{array}{l}\text { Качество межпоколенческих связей в } \\
\text { мегаполисе ниже, чем в других населенных } \\
\text { пунктах }\end{array}$ & $0,2^{*}$ & $0,18^{*}$ & $0,21^{* *}$ & $0,16^{*}$ & \\
\hline Экология мегаполиса подрывает здоровье & & & $0,17^{*}$ & & \\
\hline $\begin{array}{l}\text { Экономика мегаполиса оставляет желать } \\
\text { лучшего }\end{array}$ & $0,275^{* *}$ & $0,25^{* *}$ & $0,19 *$ & $0,2^{*}$ & \\
\hline $\begin{array}{l}\text { Безопасность в мегаполисе оставляет желать } \\
\text { лучшего }\end{array}$ & $0,336^{* *}$ & $0,25^{*}$ & & $0,22 *$ & \\
\hline
\end{tabular}

Из данных таблицы 1 можно заметить, что все суждения о негативных сторонах жизни в городе связаны с переживанием респондентами негативных эмоций и чувств. В частности, весь спектр эмоциональных переживаний вызван характером межличностных контактов в городе (навязанные, тесные контакты с чужими людьми). Интересно, что представления о разобщенности поколений и неудовлетворенность молодежи экономической жизнью в городе порождают не только беспокойство, раздражение, разочарование, но и апатию (высшая фаза в развитии состояния СП пресыщенности). Связь представлений молодых горожан о плохой экологии и переживания ими апатии косвенно свидетельствует о понимании респондентами безысходности решения этой проблемы. Данное предположение подтверждается тем, что ни одна из стратегий совладания либо избегания (см. табл.2) не образует связь с этим суждением. Молодые люди отмечают только переживание дискомфорта в многолюдных местах. Переживание тревоги, беспокойства, раздражения и разочарования участников исследования вызваны проблемами безопасности проживания в городе, повышенной стрессовой обстановкой, чрезмерной инфрорматизацией жизненного пространства в городе. 
В таблице 2 представлены результаты корреляционного анализа суждений о мегаполисе и конативных (поведенческих) проявлений СП пресыщенности. Как можно заметить, суждение о характере межличностных контактов, которое было связано с несколькими негативными переживаниями (от беспокойства до отвращения и апатии), активизирует сразу несколько стратегий совладания, связанных с ограничением коммуникаций. Интересно, что стратегия активного поиска новых источников получения удовольствия от жизни в городе образует связи со всеми периферийными элементами СП О мегаполисе (информатизация, безличный характер общения, проблемы экономики и безопасности).

Табл. 2.

Связь между негативными суждениями о мегаполисе и конативными показателями (стратегии поведения) социально-психологической пресыщенности

\begin{tabular}{|c|c|c|c|c|c|c|}
\hline $\begin{array}{l}\text { Суждения о } \\
\text { мегаполи- } \\
\text { се/стратегии } \\
\text { поведения }\end{array}$ & $\begin{array}{c}\text { Активно } \\
\text { ищу иные } \\
\text { источники } \\
\text { удовольст- } \\
\text { вия в } \\
\text { мегаполис } \\
\text { е }\end{array}$ & $\begin{array}{l}\text { Стараюс } \\
\text { ь } \\
\text { общаться } \\
\text { только с } \\
\text { самыми } \\
\text { близкими }\end{array}$ & $\begin{array}{c}\text { Стремлюс } \\
\text { ь оградить } \\
\text { себя от } \\
\text { рекламы } \\
\text { любыми } \\
\text { способами }\end{array}$ & $\begin{array}{c}\text { Не хочу } \\
\text { никого } \\
\text { видеть и } \\
\text { слышат } \\
\text { b }\end{array}$ & $\begin{array}{c}\text { Испытыва } \\
\text { ю сильное } \\
\text { желание } \\
\text { уехать } \\
\text { куда- } \\
\text { нибудь }\end{array}$ & $\begin{array}{c}\text { Я } \\
\text { испыты } \\
\text { ваю } \\
\text { диском- } \\
\text { форт в } \\
\text { людных } \\
\text { местах }\end{array}$ \\
\hline $\begin{array}{l}\text { Жизнь в } \\
\text { мегаполисе } \\
\text { сопровождается } \\
\text { большим коли- } \\
\text { чеством } \\
\text { стрессов }\end{array}$ & & $0,21^{*}$ & & $0,16^{*}$ & & \\
\hline $\begin{array}{l}\text { Информатизаци } \\
\text { я является } \\
\text { скорее минусом, } \\
\text { чем плюсом } \\
\text { жизни в } \\
\text { большом городе }\end{array}$ & $0,23^{* *}$ & & $0,17^{*}$ & & & \\
\hline $\begin{array}{l}\text { Большое } \\
\text { количество } \\
\text { межличностных } \\
\text { контактов в } \\
\text { мегаполисе } \\
\text { является } \\
\text { стрессом }\end{array}$ & & $0,22^{* *}$ & $0,21^{* *}$ & $0,16^{*}$ & & $0,24^{* *}$ \\
\hline $\begin{array}{l}\text { Безличный } \\
\text { характер } \\
\text { общения в } \\
\text { мегаполисе } \\
\text { обесценивает } \\
\text { отношения } \\
\end{array}$ & $0,18^{*}$ & & & & & \\
\hline $\begin{array}{l}\text { Экология } \\
\text { мегаполиса }\end{array}$ & & & & & & $0,18^{*}$ \\
\hline
\end{tabular}




\begin{tabular}{|l|l|l|l|l|l|l|}
\hline $\begin{array}{l}\text { подрывает } \\
\text { здоровье }\end{array}$ & & & & & & \\
\hline $\begin{array}{l}\text { Экономика } \\
\text { мегаполиса } \\
\text { оставляет желать } \\
\text { лучшего }\end{array}$ & $0,25^{* *}$ & & & & & \\
\hline $\begin{array}{l}\text { Внимание к } \\
\text { гражданам со } \\
\text { стороны властей } \\
\text { в большом горо- } \\
\text { де слишком } \\
\text { пристальное }\end{array}$ & & $0,2^{*}$ & & & $0,2^{*}$ & \\
\hline $\begin{array}{l}\text { Безопасность в } \\
\text { мегаполисе } \\
\text { оставляет желать } \\
\text { лучшего }\end{array}$ & $0,27^{* *}$ & & $0,24^{*}$ & & & \\
\hline
\end{tabular}

Они вызывают разные негативные переживания респондентов, но не их крайние формы - отвращения и апатии (потери интереса к жизни). В поиске защиты от стрессов в городской среде, пристального контроля со стороны властей, молодые люди обращаются к социальной поддержке близких людей. Попытка оградить себя от рекламы (точнее, навязанной извне, подчас в агрессивной форме, информации) в сознании респондентов связана с их представлениями о переизбытке информации и межличностных контактов в городе. Напомним, что именно чрезмерность коммуникативных контактов в мегаполисе вызвал спектр эмоциональных переживаний участников исследования.

Итак, результаты исследования позволяют подтвердить основную гипотезу. Установлено, что не смотря на позитивный характер ядра СП, периферийные суждения о негативных сторонах жизни в городе связаны с эмоциональными и поведенческими проявлениями СПП. Данный факт может быть рассмотрен как один из аргументов, объясняющих противоречивость восприятия городской среды в группе участников исследования. С одной стороны, воспринимая себя как горожанина, студента, работника, т.е. как представителя конкретной социальной группы, респонденты осознают ценность возможностей и ресурсов города, что отражается в позитивном содержании ядерного компонента их СП о мегаполисе. С другой стороны, огромный город таит в себе много того, что воспринимается молодыми людьми как источники переживаний и стрессов. Совладая с ними (или избегая их) на индивидуальном уровне, респонденты переживают разные негативные эмоции и чувства, свидетельствующие о глубине состояния СП пресыщенности - от раздражения до апатии. В перспективе настоящего исследования будет проведен анализ СП пресыщенности разных групп молодежи, выделенных на основании различий в восприятии мегаполиса. 


\section{Литература}

1. Блохин В. Н. Глобальный город: специфика жизни и трансформации личности // Социальные и пространственные измерения современного мегаполиса: Материалы IX социологических чтений памяти Валерия Борисовича Голофаста (1941-2004), 03-05 апреля 2017 года. СПБ.: "Норма". 2017. с. 94-100.

2. Дробышева Т.В., Ларионов И.В., Филинкова Е.В. Социальнопсихологическая пресыщенность молодежи условиями проживания в мегаполисе: концептуальный подход и результаты исследования // Изв. Сарат. ун-та Нов. сер. Сер. Акмеология образования. Психология развития. 2020. T. 9. № 4(36). с. 350-357. DOI: 10.18500/2304-97902020-9-4-350-357.

3. Емельянова Т. П. Городская среда в представлениях молодых москвичей: рациональное и чувственное//Социально-психологические исследования города/под ред. Т.В. Дробышевой, А.Л. Журавлева. М.: Изд-во «Институт психологии РАН». 2016. с. 105-124.

4. Емельянова Т. П. Конструирование социальных представлений в условиях трансформации российского общества. М.: Издательство "Институт психологии РАН". 2006. 400 с.

5. Заборова Е. Н., Исламова А. Ф. Город как социальное пространство // Социологические исследования. 2013. №2. с. 97-101.

6. Покатиловская Е.Н., Хохлова Н.И. Шибаева Л.В. "Диффузность" городской идентичности учащейся молодежи как ресурс жизнеспособности "моногорода" // Способности и ментальные ресурсы человека в мире глобальных перемен. М.: Институт психологии РАН. 2020. c. 830-837.

7. Савина О.О., Баранова В.А. Средовые условия в формировании городской идентичности новых жителей мегаполиса // Психология. Историко-критические обзоры и современные исследования. 2017. Том 6. № 2А. с. 171-180.

8. Соловьева А.Н., Соловьева Т.А. Образ города в структуре социальных представлений о Севере (на примере Архангельска) // Вестн. Сев.(Арктич.) федер. ун-та. Сер.: Гуманит. и соц. науки. 2019. № 6. С. 112-120. DOI: 10.17238/issn2227-6564.2019.6.112

9. Abric J.C. Central system, peripheral system: Their functions and roles in the dynamic of social representations // Papers on Social Representations. 1993. V. 2. pp. $75-78$. 


\section{REPRESENTATIONS OF MEGACITY AND SOCIAL-PSYCHOLOGICAL SATIETY OF YOUNG CITY DWELLERS WITH LIVING CONDITIONS}

Drobysheva T.V., Larionov I.V. (Institute of Psychology RAS, Moscow, Russia)

The article deals with the problem of the relationship between social and psychological satiety and social ideas about the metropolis. The contradictory perception of young people living conditions in a metropolis is explained by the fact that the core and periphery of social representation include judgments of different modality. A connection was found between elements of the periphery of representation and indicators of socio-psychological satiety. It is shown that the satiety of young people with living conditions in the city is associated with their perception of the problematic aspects of life in the metropolis. The choice of strategies for coping with the state of satiety is determined by the respondents' experience of a range of negative emotions and feelings.

Keywords: social-psychological satiety, social perceptions, social psychology of the city. 